\title{
RELATOS DE EXPERIÊNCIAS DE EX-ESTUDANTES DE PORTUGUÊS LÍNGUA ESTRANGEIRA: A COCONSTRUÇÃO DO CONHECIMENTO POR MEIO DA PESQUISA NARRATIVA
}

\author{
RELATOS DE EXPERIENCIAS DE EX-ESTUDIANTES DE PORTUGUÉS LENGUA \\ EXTRANJERA: LA CO-CONSTRUCCIÓN DEL CONOCIMIENTO POR MEDIO DE LA \\ INVESTIGACIÓN NARRATIVA
}

\begin{abstract}
ACCOUNTS ON EXPERIENCES OF FORMER STUDENTS OF PORTUGUESE AS A FOREIGN LANGUAGE: THE CO-CONSTRUCTION OF KNOWLEDGE THROUGH NARRATIVE INQUIRY
\end{abstract}

\author{
Luís Eduardo WEXELL-MACHADO ${ }^{1}$ \\ Lilian ALCARAZ ${ }^{2}$ \\ Irma BENÍTEZ ${ }^{3}$
}

RESUMO: Este trabalho mapeou a experiência de três ex-alunos universitários de português língua estrangeira, graduados pela Faculdade de Ciências Exatas e Naturais da Universidade Nacional de Assunção, Paraguai, que, no momento da pesquisa, estavam cursando PósGraduação no Brasil. Suas experiências foram analisadas em dois planos: o processo de aprendizagem no Paraguai e o processo de consolidação da língua, no Brasil. O corpus foi constituído por narrativas de aprendizagem recolhidas por meio de entrevistas com a utilização da Pesquisa Narrativa como meio e método de trabalho. Os dados foram codificados e analisados em cruzamento com o conceito de Espaço Tridimensional. Os resultados apontam para a insuficiência da carga horária; para a necessidade de desenvolvimento da autonomia dos estudantes e de materiais que ampliem as oportunidades de estudo fora da sala de aula, com o uso das novas tecnologias e para a necessidade de maior contato dos estudantes com falantes nativos.

PALAVRAS-CHAVE: Português língua estrangeira. Pesquisa narrativa. Experiência.

RESUMEN: Este trabajo mapeó la experiencia de tres ex-alumnos universitarios de portugués lengua extranjera, recibidos por la Facultad de Ciencias Exactas y Naturales de la Universidad Nacional de Asunción, Paraguay, que, en el momento de esta investigación, estaban cursando el Post-grado en Brasil. Sus experiencias fueron analizadas en dos niveles: el proceso de aprendizaje, en Paraguay; y el proceso de consolidación de la lengua, en Brasil. El corpus fue constituido por narrativas de aprendizaje recolectadas por medio de entrevistas

${ }^{1}$ Universidade Autónoma de Assunção (UAA). Assunção, Paraguai. Professor de Português Língua Estrangeira e
Coordenador do Grupo de Investigação em Educação, Linguagem e Tecnologia - PRODESSE. ORCID:
<https://orcid.org/0000-0002-2966-245X>. E-mail: lewmachado@ @mail.com
${ }^{2}$ Universidade Autónoma de Assunção (UAA). Assunção, Paraguai. Professora de Português Língua Estrangeira
e Pesquisadora Junior do Grupo de Investigação em Educação, Linguagem e Tecnologia - PRODESSE. ORCID:
<https://orcid.org/0000-0003-3962-1501>. E-mail: lilianalcaraz40@gmail.com
${ }^{3}$ Universidade Autónoma de Assunção (UAA). Assunção, Paraguai. Professora de Português Língua Estrangeira
e Pesquisadora Junior do Grupo de Investigação em Educação, Linguagem e Tecnologia - PRODESSE. ORCID:
<https://orcid.org/0000-0002-2595-7672>. E-mail: irma_benitez62@ hotmail.com 
con la utilización de la Investigación Narrativa como medio y método de trabajo. Los datos fueron analizados en cruce con el concepto de Espacio Tridimensional. Los resultados apuntan para la insuficiencia de la cantidad de horas; para la necesidad de desarrollo de la autonomía de los estudiantes y de materiales que agreguen más oportunidades de estudio fuera del aula con el uso de las nuevas tecnologías y para la necesidad de mayor contacto de los estudiantes con hablantes nativos.

PALABRAS CLAVE: Portugués lengua extranjer. Investigación narrativa. Experiencia.

ABSTRACT: Part of a research project in learning narratives, this paper tries to map the experience of three former university students of Portuguese as a foreign language (PLE), who graduated from the College of Exact and Natural Sciences (FaCEN), Paraguay, and, at the time of this research, were Post-Graduate students in Brazil. Their experiences were analyzed in two levels: their learning process in Paraguay and their consolidation of the language, in real context of use, in Brazil. The corpus was constituted by learning narratives collected through interviews with the use of Narrative Inquiry as means and method of work. The data was analyzed and coded in combination with the concept of Three-Dimensional Space. The results points to the insufficient number of hours dedicated to PLE classes; to the need to develop students' autonomy and, also, materials that expand the opportunities for study outside the classroom using the new technologies that focus on specific purposes and; for greater contact between students and native speakers.

KEYWORDS: Portuguese as a foreign language. Narrative Inquiry. Experience.

\section{Introdução}

O objetivo dessa pesquisa foi descrever as experiências de aprendizagem de três exestudantes de português língua estrangeira e o uso dessa língua em contexto de L1. Os três exestudantes cursaram a matéria de português, como disciplina eletiva, durante a graduação na Faculdade de Ciências Exatas e Naturais da Universidade Nacional de Assunção, Paraguai, e a utilizaram, posteriormente, em sua estadia no Brasil durante curso de pós-graduação em universidades brasileiras.

Buscamos descrever as características da experiência dos três ex-estudantes de português língua estrangeira, com a finalidade de fornecer aos professores de idiomas um melhor entendimento sobre as necessidades de estudantes universitários que cursam línguas estrangeiras como matéria curricular em seus cursos de graduação e que visem realizar cursos de pós-graduação no Brasil e, com isso, oferecer-lhes insumos para o desenvolvimento de melhores condições para o processo de ensino e aprendizagem, e instrumentos mais eficazes que deem suporte ao desenvolvimento dos estudantes, tanto no aspecto linguístico quanto sociocultural. 
Os três ex-estudantes foram nomeados como Cooperadores 1,2 e 3 e possuem as seguintes características: Cooperador 1, sexo feminino, formada em Tecnologia de Produção e cursa Mestrado em Engenharia de produção na Universidade Federal do Paraná (UFPR) mediante uma bolsa da OEA-Universidades do Grupo de Coimbra. Ela cursou português I e II como matérias eletivas na faculdade. O Cooperador 2, sexo feminino, formada em Biologia, cursa Mestrado em Biologia de Água Doce e Pesca Interior no INPA, Manaus. Ela participou, durante seis meses, de mobilidade estudantil, no Rio de Janeiro, durante sua graduação e ao seu retorno, cursou as matérias de português I e II como matérias eletivas. O Cooperador 3, sexo masculino, formado em Física, fez os cursos de português I e II como matérias eletivas. Inicialmente, cursou mestrado em Física na Universidade Estadual de Londrina (UEL) e, no momento desta pesquisa, cursava o doutorado no Centro Brasileiro de Pesquisas Físicas (CBPF), no Rio de Janeiro.

Considerar as experiências de ex-estudantes de português língua estrangeira durante seu processo de formação na língua e sua experiência de uso dessa língua em ambiente de imersão, com objetivos voltados para a formação acadêmica, visa estabelecer um ponto de apoio para professores que se defrontem com esse mesmo desafio. Embora as experiências aqui tipificadas não sejam generalizáveis, configuram-se em um indicativo que pode ser tomado como ponto de reflexão ao tratar-se de histórias de vidas que são comuns a muitos que passam por experiências semelhantes. Por isso, esta pesquisa também tratou de verificar quais são as experiências mais relevantes narradas pelos ex-estudantes paraguaios de português como língua estrangeira, sobre seu processo de ensino-aprendizagem da língua e da vivência dessa língua em contexto real de uso.

Procuramos detalhar as experiências dos ex-estudantes baseando-nos em suas narrativas de vida e nos valemos da Pesquisa Narrativa como instrumento de coleta de dados e como meio de análise do processo. Nesse sentido, compactuamos com Clandinin e Connelly (2015) que, com base em Dewey (1938), esclarecem que a experiência se dá sempre em duas dimensões: a pessoal e a social.

Em ambas dimensões os indivíduos atuam em interação e estão socialmente contextualizados, sempre preservando o ponto de vista do narrador, seja ele aquele que conta sua própria história, seja ele aquele que a ouve e a compartilha, envolvendo a narrativa original na sua própria narrativa: o ponto de vista de quem contou, dentro do ponto de vista daquele que a reconta. O papel do pesquisador é interpretar os textos e, imediatamente a partir deles, criar novamente outros textos. 
De acordo com Clandinin e Connelly (2015) a pesquisa narrativa utiliza-se de um espaço tridimensional: interação, que é pessoal e social; continuidade, que abarca passado, presente e futuro e; situação, a noção de lugar.

Entende-se por pessoal: os sentimentos, esperanças, desejos, reações estéticas e disposição moral do pesquisador ou do participante. Por social, as condições existenciais, o ambiente, forças e fatores subjacentes e pessoais que participam e formam o contexto dos indivíduos. A interação, tanto no aspecto individual quanto no aspecto social, leva sempre presente a noção de continuidade, que se marca a partir do passado, presente e futuro e; o lugar, baseado na situação:

\begin{tabular}{|ll|}
\multicolumn{1}{c}{ Quadro 1 - O Espaço Tridimensional } \\
\hline Aspecto & Características \\
Interação & Pessoal/ Social \\
Continuidade & Passado/ Presente/ Futuro \\
Situação & Lugar \\
\hline
\end{tabular}

Fonte: Adaptado de Clandinin e Connelly, 2015.

O Espaço tridimensional é uma das bases que utilizamos para a compreensão e análise das narrativas; a outra base é a compreensão da relação que se estabelece entre as vozes dos pesquisadores e dos pesquisados. Já que a investigação narrativa requer colaboração na explicação das histórias, as vozes dos pesquisados e dos pesquisadores se unem nos relatos das experiências (CUNHA, 2009), e as pessoas envolvidas no processo são a corporificação dessas histórias vividas, vidas compostas que constituem e são constituídas por narrativas social e culturalmente situadas (CLANDININ; CONNELLY, 2015).

\section{Método}

Este trabalho está baseado em um estudo de caso, com o uso da Pesquisa Narrativa como instrumento de coleta de dados e como método de estruturação da pesquisa, o que nos permitiu uma compreensão mais próxima às experiências dos estudantes, sobre seu processo de ensino- 
aprendizagem e as dificuldades enfrentadas na hora da aplicação da língua em contexto real de uso.

A pesquisa foi realizada dentro de um projeto de investigação conduzido por um professor da Licenciatura em Língua Portuguesa do Instituto Superior de Línguas e duas professoras paraguaias em pré-serviço.

A pesquisa foi estruturada em três fases. Na primeira fase, fizemos a revisão da bibliografia existente referente aos diferentes aspectos teóricos do objeto da pesquisa; na segunda fase, criamos uma matriz de análise a partir do processamento dos dados coletados por meio das narrativas; na terceira fase, realizamos o cruzamento da matriz elaborada a partir da codificação das narrativas com a teoria da Pesquisa Narrativa, ou seja, com o conceito de espaço tridimensional, onde também se dá a relação de compreensão entre as histórias contadas pelos pesquisados em conjunto com a voz dos pesquisadores.

A matriz, elaborada na segunda fase, foi composta por uma codificação indutivamente criada a partir da leitura da transcrição das entrevistas e com base nos elementos mais reincidentes e comuns às três narrativas, além dos aspectos que mais chamaram a atenção dos pesquisadores, de acordo com suas experiências no ensino da língua. A codificação foi elaborada com o uso da ferramenta de análise qualitativa Atlas TI.

Também elaboramos um perfil dos futuros colaboradores, que, por questões de privacidade, são aqui denominados como Cooperador 1, Cooperador 2 e Cooperador 3; pseudônimos pelos quais eles foram identificados na pesquisa. As histórias ouvidas foram recontadas na discussão dos resultados e na elaboração das conclusões e recomendações. Todos os colaboradores assinaram o Termo de Consentimento Livre e Esclarecido e a pesquisa se orientou de acordo com o Comitê de Ética em Publicações (COPE).

As entrevistas gravadas foram posteriormente transcritas para um editor de texto com o objetivo de facilitar o processo de codificação. Do Cooperador 1 transcrevemos dezesseis páginas, do Cooperador 2, quatorze páginas e do Cooperador 3 obtivemos uma transcrição de quatro páginas. Mantivemos contato com os Cooperadores após as entrevistas para tirar dúvidas e esclarecer alguns pontos das entrevistas. Os Cooperadores foram selecionados para a pesquisa por conveniência.

Para proceder à interpretação dos dados, partimos do aspecto tridimensional da pesquisa narrativa e da codificação elaborada a partir dos textos transcritos das entrevistas. O produto do processo de codificação, indutivamente construído a partir dos dados transcritos, resultou em duas dimensões temáticas: a que descreve o processo de formação dos ex-estudantes, a 
aprendizagem da língua no Paraguai e a que descreve o processo de adaptação e uso da língua no contexto brasileiro.

Essas duas dimensões receberam os seguintes nomes: dimensão 1, experiências evidenciadas nas narrativas dos ex-alunos de PLE sobre sua formação e seu processo de ensinoaprendizagem no Paraguai; dimensão 2, dificuldades e necessidades linguísticas e culturais de ex-estudantes de PLE nos seus primeiros meses em contexto brasileiro.

Os fragmentos selecionados a partir da codificação das narrativas foram distribuídos entres as duas dimensões mencionadas em quatro subtemas, dois subtemas para cada dimensão: Processo de ensino e aprendizagem (quadro 2); Materiais didáticos e novas tecnologias (quadro 3), relacionados com a primeira dimensão temática e Aplicação da aprendizagem em seu contexto real de uso (quadro 4); Dificuldades linguísticas e culturais em contexto brasileiro (quadro 5) relacionados com a segunda dimensão temática.

\section{Resultados}

Por questões relacionadas à dimensão desse artigo, as transcrições completas, em espanhol, estão publicadas como dataset em Mendeley Data (WEXELL-MACHADO; ALCARAZ; BENÍTEZ, 2019).

As narrativas foram divididas em dois grandes blocos e organizadas em 4 tabelas, a partir de fragmentos das transcrições e de acordo com as codificações em quatro categorias, que apresentamos a continuação. As transcrições foram feitas preservando a fala dos Colaboradores com alguns pequenos ajustes, mas sem a preocupação de corrigir erros de concordância, colocação pronominal etc.

1. Experiências evidenciadas nas narrativas dos ex-alunos de PLE sobre sua formação e seu processo de ensino-aprendizagem no Paraguai.

Quadro 2 - Processo de ensino e aprendizagem

\section{Fragmentos}

Fragmento 1 “... é fácil para nós entendermos o português, porque consumimos muita música brasileira, propaganda." (Cooperador 1).

Fragmento 2 "Eu só estudei Português um ano." (Cooperador 2).

Fragmento 3 "Eu diria que foi muito fácil aprender a língua, não sei se é por causa da semelhança ou porque já fiz o curso, mas não me custou muito." (Cooperador 3 ).

Fragmento 4 "Eu tinha a pequena base da universidade, tive que fazer um exame de certificação da língua portuguesa e, sem ter uma base, tive que estudar assim." (Cooperador 1). 
Fragmento 5 “... sim, isso me ajudou, quando voltei já falei bem, mas lá meu português estava melhorando bastante." (Cooperador 2).

Fragmento 6 "Isso me ajudou de certa forma para pelo menos entender o que as pessoas me disseram ou o que as pessoas tentaram me dizer." (Cooperador 3 ).

Fragmento 7 “... eu estudei o português na faculdade com o professor e depois fiz o Celpe Bras.” (Cooperador 1).

Fragmento 8 "Seis meses, lá eu fiz Português com o professor e aprendi muito porque, outra coisa é quando você lê, você entende". (Cooperador 2).

Fragmento 9 “... a língua que eles usaram é o que eu deveria ter usado não foi o que eu aprendi aqui." (Cooperador 3).

Fonte: Extraídos do Dataset de Wexell-Machado, L. E.; Alcaraz, L.; Benitez, I., 2019.

Quadro 3 - Materiais didáticos e novas tecnologias

\begin{tabular}{|c|}
\hline \\
\hline $\begin{array}{l}\text { Fragmento } 10 \text { “... Eu acho que os materiais são o básico, eu não posso dizer que eles são suficientes, o } \\
\text { que eu vi na faculdade, foi muito simples, básico demais, foram básico do básico, o mínimo que pode } \\
\text { ser dado, eu tive que procurar os materiais na internet, YouTube, mais na internet o que eu achei os } \\
\text { materiais e estudei sozinha. (Cooperador } 1 \text { ). } \\
\text { Fragmento } 11 \text { “...Sim os materiais foram bastante, diversos, para ajudar a ter um aprendizado } \\
\text { (Cooperador } 2 \text { ). } \\
\text { Fragmento } 12 \text { “...Sim, temos acesso aos materiais para complementar na internet, é questão de procurar } \\
\text { sozinho. (Cooperador } 3 \text { ). }\end{array}$ \\
\hline $\begin{array}{l}\text { Fragmento } 13 \text { "... Serviram-me bastante como eu te contei que tudo estava online, eu fiz um curso de } \\
\text { suporte que é o teste de proficiência em língua estrangeira CELPE-Bras, lá também me deu alguns } \\
\text { materiais básicos a partir desses materiais tive que ir para trás. Então tudo assim, livros, vídeos do } \\
\text { YouTube, textos que encontrei em toda a internet e que me ajudaram muito, muito porque achei textos } \\
\text { de anos anteriores do CELPE-Bras e estudei com base nisso e aí posso dizer que os materiais que são da } \\
\text { internet, que fui eu quem procurou, me serviu mais do que os que eles me deram no curso da faculdade } \\
\text { e também no CELPE-Bras" (Cooperador 1). } \\
\text { Fragmento } 14 \text { "... Sim vídeos, áudios, música tudo valeu. } \\
\text { Contribuiu de uma forma boa para o aprendizado do português, mas, isso, uma procura, não foi facilitada } \\
\text { durante o ensino "(Cooperador } 2) \text {. } \\
\text { Fragmento } 15 \text { "... Sim, de todos os modos o ensino foi para entender alguma coisa, não dá para um bom } \\
\text { desempenho" (Cooperador } 3) .\end{array}$ \\
\hline $\begin{array}{l}\text { Fragmento } 16 \text { “... A maneira que eu complementava era estudando sozinha, procurando e praticando } \\
\text { muitas vezes no meu caso de anos anteriores e na aula perguntando aos professores da FaCEN, Ilpor” } \\
\text { (Cooperador } 1 \text { ). } \\
\text { Fragmento } 17 \text { “... Eu complementei com bastante leitura, fala com brasileiros, a comunicação escrita e } \\
\text { a leitura foram de muita ajuda” (Cooperador } 2 \text { ). } \\
\text { Fragmento } 18 \text { “... Posso dizer que eu complementei estando já no Brasil falando com as pessoas. } \\
\text { (Cooperador } 3 \text { ). }\end{array}$ \\
\hline
\end{tabular}

Fonte: Extraídos do Dataset de Wexell-Machado, L. E.; Alcaraz, L.; Benitez, I. 2019.

2. Dificuldades e necessidades linguísticas e culturais de ex-estudantes de PLE nos seus primeiros meses em contexto brasileiro. 
Quadro 4 - Aplicação da aprendizagem em seu contexto real de uso

\begin{tabular}{l}
\hline Fragmentos \\
\hline Fragmento 19 “... eu tive que fazer uma apresentação em Português, foi meio difícil, e todo mundo riu \\
e eu disse: alguma coisa estou dizendo errado?” (Cooperador 1). \\
Fragmento 20 "Não entendia nada porque eles falam rápido, essa história é falsa que o espanhol é igual \\
ao português”. (Cooperador 2). \\
Fragmento 21 "Para entrar em conversas é o que mais me custou, a única coisa que eu poderia fazer é \\
entender o que eles disseram”. (Cooperador 3). \\
\hline Fragmento 22 "Existem alguns professores que têm consideração, como professores que falam o \\
espanhol”. (Cooperador 1). \\
Fragmento 23 "Falei com todos os meus professores, que não falava, que não entendia e não sabia \\
escrever, então, que por favor, façamos o exame em espanhol”. (Cooperador 2). \\
Fragmento 24 “... academicamente, há muita diferença, como os professores dão sua aula, na maneira \\
de transmitir conhecimento”. (Cooperador 3). \\
Fragmento 25 “... sim, porque depende muito de onde você aprendeu a linguagem para manter isso. Se \\
você aprende Português com um [alguém] do Rio de Janeiro ou do Paraná”. (Cooperador 1). \\
Fragmento 26 “... dos diferentes estados, comecei a aprender em Manaus, lá comecei a aprender sobre \\
os vários lugares do Brasil. Meu ouvido pegou”. (Cooperador 2). \\
Fragmento 27 “... sentia que havia muitas formas de falar, mas, ao mesmo tempo era português”. \\
(Cooperador 3 ).
\end{tabular}

Fonte: Extraídos do Dataset de Wexell-Machado, L. E.; Alcaraz, L.; Benitez, I. 2019.

\section{Quadro 5 - Dificuldades linguísticas e culturais em contexto brasileiro}

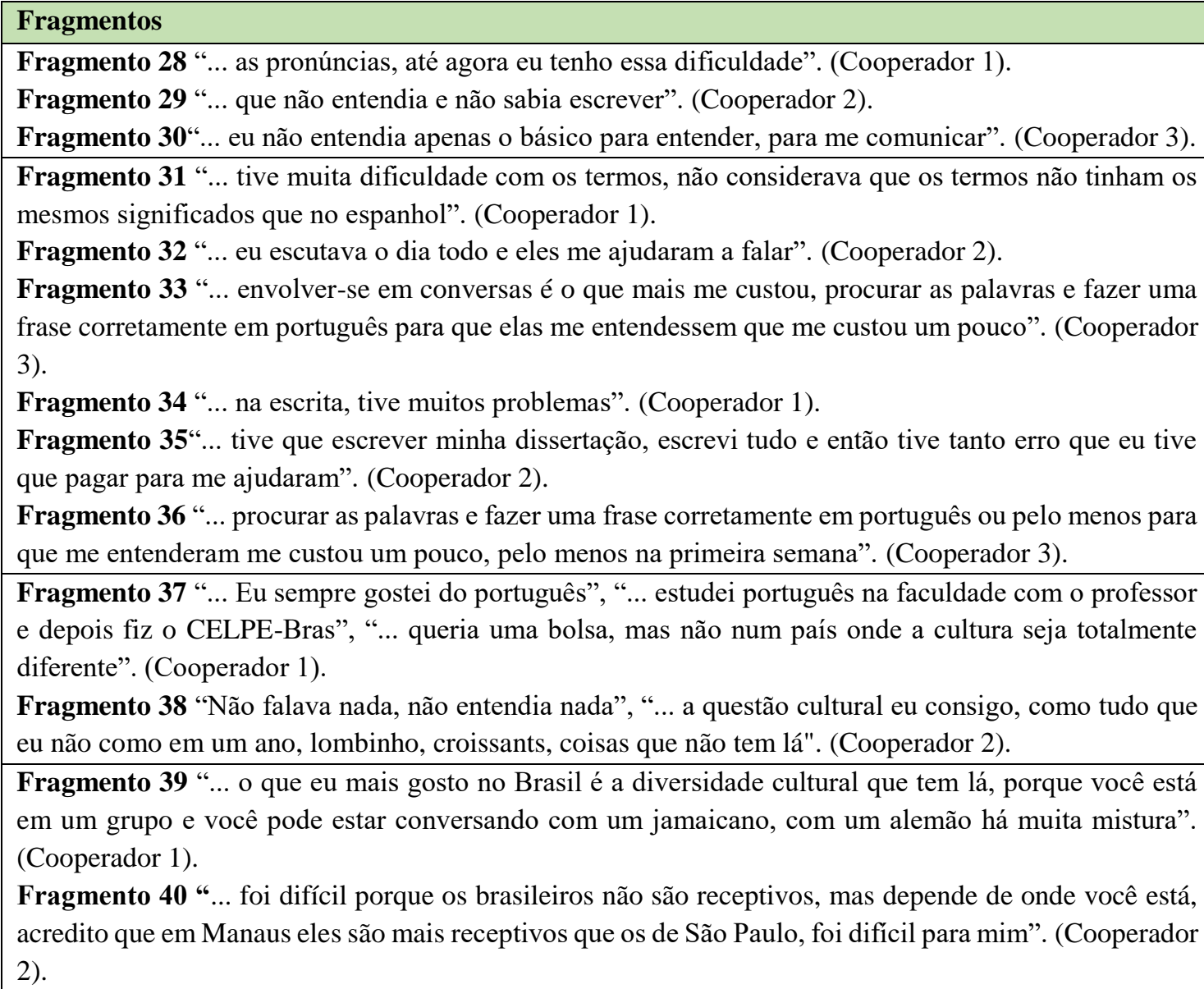


Fragmento 41 “... eles foram muito legais comigo em todos os momentos, na verdade, eles estavam interessados em pessoas que não eram brasileiras, mas eram estrangeiras". (Cooperador 3 ).

Fonte: Extraídos do Dataset de Wexell-Machado, L. E.; Alcaraz, L.; Benitez, I. 2019.

\section{Discussão}

De acordo com Clandinin e Connelly (2015), na pesquisa narrativa a experiência é um processo de construção e reconstrução de sentidos e significados que se realiza por meio das histórias de vida. Por meio das narrativas, tivemos acesso às histórias de vida dos Cooperadores e, logramos codificar, na transcrição de seus relatos, suas dificuldades e necessidades no campo da língua e da cultura em dois momentos: durante a fase de aprendizagem de PLE, no Paraguai, e nos seus primeiros meses de uso da língua em contexto brasileiro.

Essas narrativas estão, portanto, divididas em duas dimensões: a paraguaia, onde se iniciou o aprendizado, e a brasileira, onde o aprendizado da língua se consolidou. Os textos foram codificados indutivamente a partir da leitura da transcrição das entrevistas em quatro categorias: Processo de ensino e aprendizagem (quadro 2); Materiais didáticos e novas tecnologias (quadro 3); Aplicação da aprendizagem em seu contexto real de uso (quadro 4) e; Dificuldades linguísticas e culturais em contexto brasileiro (quadro 5).

A partir das narrativas dos Cooperadores 1 e 3 , pudemos notar que a experiência sobre o processo de ensino e aprendizagem da língua revela uma expectativa, a priori, de que, para o hispano-falante, aprender português é algo que não requer muito esforço. Nos fragmentos das conversas, que apresentamos a seguir, verifica-se que: “(...) é fácil para nós entendermos o português” (Fragmento 1, Cooperador 1) e; “(...) eu diria que foi muito fácil aprender a língua” (Fragmento 3, Cooperador 3).

A experiência relacionada com o uso da língua em processo de interação em sala de aula e no cotidiano paraguaio, durante a fase de aprendizagem de português, parecia ser algo relativamente simples para os Cooperadores 1 e 3 , já que há uma grande proximidade entre o português e o espanhol, proximidade da qual deriva a crença sobre a suposta facilidade de o falante de um dos idiomas aprender o outro.

Essa percepção, com relação a facilidade de se aprender português, é bastante recorrente entre os paraguaios. Inclusive as pesquisadoras participantes desse projeto de pesquisa compartilhavam dessa mesma percepção ao início de seu processo de formação como professoras de português. Ao desenvolver habilidades para entender algumas músicas e assistir algumas propagandas na televisão veiculadas em português, já permitia, naquele momento e 
situação, a capacidade de usar a língua portuguesa com efetividade diante das demandas sociais daquele contexto: pouco contato com falantes nativos; situações controladas de uso da língua, baixo nível de interação etc. Não havia, nesse momento, consciência sobre as implicações que as necessidades futuras de uso da língua demandariam. Lembramos que, de acordo com Clandinin e Connelly (2015), na pesquisa narrativa, a relação social é a combinação entre o indivíduo e o ambiente e que, portanto, o contexto social em que se movimenta o indivíduo é um fator determinante de suas necessidades práticas e, por conseguinte, de sua necessidade de aprender uma língua estrangeira.

É fato que tanto a proximidade das línguas - espanhol e português - como a proximidade geográfica entre Paraguai e Brasil fazem com que a língua portuguesa soe familiar para os paraguaios, mais ainda para aqueles que a estudam com algum objetivo específico.

Diferentemente, o fragmento 2 da narrativa do Cooperador 2 mostrou posicionamento oposto ao relatar que “(...) só estudei português um ano”. Essa diferença de apreciação pode ser o resultado de o Cooperador possuir experiência de estudar português como língua estrangeira em contexto real de uso, durante intercâmbio discente no Brasil, anteriormente ao estudo da língua na universidade, e, portanto, já ter conhecimento sobre a realidade das condições de interação em contextos reais de uso da língua e da necessidade de maior dedicação à aprendizagem.

Considerando as experiências dos Cooperadores 1 e 3, entendemos que sua percepção de que a língua era de fácil aprendizagem se deve a pouca exigência da língua em seu contexto de uso, tanto no que se refere às habilidades orais quanto escritas. Os fragmentos que estão mais adiante demonstram suas dificuldades de uso da língua quando já inseridos no contexto brasileiro.

Segundo a narrativa do Cooperador 1, percebemos que, de acordo com sua experiência, o aprendizado de português não foi suficiente, motivo pelo qual teve que fazer outro curso complementar para realizar a prova do Certificado de Proficiência em Língua Portuguesa para Estrangeiros - CELPE-Bras ${ }^{4}$-, prova oficial do Ministério de Educação do Brasil; de nosso ponto de vista, é possível, que com o ensino realizado durante suas aulas de português na universidade paraguaia, suas expectativas não tenham sido preenchidas, já que se percebe essa visão negativa no fragmento 4 da narrativa: “(...) eu tinha a pequena base da universidade, tive que fazer um exame de certificação da língua portuguesa" (Cooperador 1). Acreditamos que uma das causas prováveis da frustração com relação aos estudos de português durante sua 
graduação seja a carga horária insuficiente e/ou a rigidez da estrutura do curso para promover as oportunidades necessárias para a aprendizagem específica desejada.

A experiência narrada pelos fragmentos 1 e 3 das narrativas dos Cooperadores, de que a aprendizagem e uso da língua portuguesa seria algo de fácil manejo é recorrente entre os paraguaios. É comum o comentário de que a língua portuguesa é um "espanhol mal falado". As professoras em pré-serviço, coautoras deste trabalho, também experimentaram essa vivência ao ingressar no curso de formação de professores, que já no seu início produziu uma mudança de suas percepções, ao receberem aulas de cinco professores de diferentes Estados brasileiros e ao lidar com realidades culturais e linguísticas diversas em ambientes mais complexos.

No recorte da narrativa do Cooperador 3, sobre a suficiência do aprendizado da língua, desde um olhar retrospectivo, lê-se, por exemplo: “(...) é o que eu deveria ter usado; não foi o que eu aprendi aqui" (Fragmento 9, Cooperador 3). Com "aqui" o Cooperador se refere ao Paraguai, lugar da entrevista, e, com isso, podemos identificar novamente certa frustração causada pelo descompasso entre o estudado e as necessidades de uso durante seu curso de pósgraduação no Brasil, algo bastante reincidente nas narrativas e que nos chama a atenção para a necessidade de pensar em soluções inovadoras que possam, se não resolver, pelo menos melhorar o nível da experiência.

Ao analisar as histórias das experiências de aprendizagem de nossos Cooperadores, verificamos que, com a disciplina cursada no período de graduação, eles não conseguiram obter a fluência que necessitavam na língua.

Com relação aos materiais didáticos e as novas tecnologias, nos fragmentos das narrativas dos Cooperadores, nota-se uma ambiguidade que não deixa claro se a experiência com esses materiais foi ou não satisfatória: “(...) eu acho que os materiais são o básico (...) básico demais, foram básicos do básico (...) eu tive que procurar os materiais na internet, YouTube, mais na internet, o que eu achei, os materiais, e estudei sozinha" (Fragmento 10, Cooperador 1); “(...) sim os materiais foram bastante, diversos para ajudar a ter um aprendizado" (Fragmento 11, Cooperador 2); “(...) sim, temos acessos aos materiais para complementar na internet, é questão de procurar sozinho" (Fragmento 12, Cooperador 1). A maneira como cada qual percebe e constrói o relato de suas experiências e os vieses que os levam a privilegiar certo ponto de vista em detrimento de outro é o resultado dos interesses e das relações momentâneas, daquilo que objetivam conquistar. Assim a experiência se contextualiza na relação entre esses interesses próprios de cada um e seu contexto.

O que ressalta dos fragmentos anteriores é a necessidade do desenvolvimento da autonomia dos estudantes, embora o curso também deva orientar e mostrar possibilidades 
viáveis no sentido de complementar sua formação e, se possível, auxiliá-los na utilização desses recursos. Quando o estudante tem a iniciativa ou a orientação para buscar por sua própria conta aquilo que lhe falta, ele constrói uma experiência mais positiva, como podemos notar nos seguintes fragmentos dos Cooperadores: “(...) textos que encontrei em toda a internet e que me ajudaram muito, muito porque achei textos de anos anteriores da CELPE-Bras e estudei com base nisso e aí posso dizer que os materiais que são da internet, que fui eu o que procurou me serviu mais do que os que eles me deram no curso da faculdade e também nas CELPE-Bras" (Fragmento 13, Cooperador 1); “(...) sim, vídeos, áudios, música, tudo valeu. Contribuiu de uma forma boa para o aprendizado do português, mas, isso, nós procuramos, não foi facilitado durante o ensino” (Fragmento 14, Cooperador 2); “(...) sim, de todos os modos o ensino foi para entender alguma coisa, não dá para um bom desempenho" (Fragmento 15, Cooperador 1).

Os fragmentos 13, 14 e 15 nos permitem perceber que as experiências relacionadas com carências: de recursos, de tempo ou de materiais foram suprimidas pela iniciativa e autonomia dos estudantes ao recorrerem ao uso da internet para que pudessem atingir seus objetivos, "expandindo" a sala de aula e incorporando novos conhecimentos. Essa experiência nos levou a refletir sobre a necessidade de preparar conteúdos e materiais que possam ser administrados tangencialmente às aulas presenciais (WEXELL-MACHADO; MATTAR, 2017) e que possam ser disponibilizados aos estudantes por meio da internet.

E assim, nossos Cooperadores vão complementando, cada um seu aprendizado, conforme corroboram os seguintes fragmentos: "... eu complementava estudando sozinha" (Fragmento 16, Cooperador 1); “(...) eu complementei com bastante leitura” (Fragmento 17, Cooperador 2); “(...) eu complementei estando já no Brasil falando com as pessoas” (Fragmento 18, Cooperador 3).

A característica mais marcante dos Cooperadores está na autodeterminação e no estímulo a ação, eles buscaram respostas para todas as dificuldades que se apresentaram, focando sempre em seus objetivos.

A seguir, apresentamos as narrativas dos Cooperadores e as analisamos a partir da dimensão do uso da língua em contexto brasileiro, tratando de apresentar as experiências dos ex-estudantes de PLE sobre suas dificuldades e necessidades linguísticas e culturais em contexto real de uso conforme os quadros 4 e 5 .

A narrativa dos Cooperadores, revelada nos fragmentos, relacionada com a aplicação da língua no cotidiano brasileiro mostra as dificuldades vividas, como ilustram os seguintes fragmentos: “(...) foi meio difícil, e todo mundo riu” (Fragmento 19, Cooperador 1); “(...) não 
entendia nada porque eles falam rápido” (Fragmento 20, Cooperador 2); “(...) para entrar em conversas é o que mais me custou" (Fragmento 21, Cooperador 3).

A experiência inicial de uso da língua estrangeira, no contexto brasileiro, mostra a defasagem entre o nível alcançado e o nível de proficiência necessário para a interação no contexto de aplicação. Os fragmentos também mostram experiências em que a comunicação não se realizou adequadamente, causando desconforto: "todo mundo riu" (Fragmento 19, Cooperador 1). Os Cooperadores, neste momento, tomaram consciência de não possuir a formação suficiente para “entrar em conversas" (Fragmento 21, Cooperador 3).

No que se refere ao ambiente acadêmico, os problemas de comunicação foram ainda maiores: “(...) existem alguns professores que têm consideração” (Fragmento 22, Cooperador 1); “(...) falei com todos os meus professores que não falava, que não entendia” (Fragmento 23, Cooperador 2); “(...) há muita diferença como os professores ministram suas aulas” (Fragmento 24, Cooperador 3).

Vemos, por meio dos fragmentos, que recorrer à compreensão dos professores foi um recurso estratégico de muita importância para poder vencer os primeiros desafios da adaptação à língua. Essa experiência chamou nossa atenção sobre a necessidade de preparar os estudantes para situações como a relatada.

Os Cooperadores, já em processo de interação no contexto brasileiro, começam a refletir sobre as particularidades da língua. Passam a perceber, com o passar do tempo, as diferentes características regionais da população brasileira e seus diferentes sotaques: “(...) depende muito de onde você aprendeu a linguagem" (Fragmento 25, Cooperador 1); “(...) lá, comecei a aprender sobre os vários lugares do Brasil. Meu ouvido pegou" (Fragmento 26, Cooperador 2); “(...) sentia que havia muitas formas de falar” (Fragmento 27, Cooperador 3). Essa nova experiência, que possibilitou diferenciar os diversos falares, veio acompanhada de um sentimento de realização em função do desenvolvimento das habilidades comunicativas: “(...) meu ouvido pegou”; “(...) sentia que havia muitas formas”.

Ao verificar o programa do curso de português ministrado aos Cooperadores durante seus cursos de graduação, percebemos que os ex-estudantes não tiveram muita oportunidade de vivenciar, em sala de aula, as variações regionais da língua portuguesa do Brasil, embora expressem o importante que foi, para eles, a experiência do reconhecimento dos diversos falares, algo que deveria, de acordo com as narrativas, ser privilegiado nos cursos de formação de língua.

Ao longo de suas estadias no Brasil e até o momento das entrevistas, os Cooperadores manifestam suas dificuldades ao interagirem com brasileiros com o uso da língua portuguesa: 
“(...) as pronúncias, até agora tenho essa dificuldade” (Fragmento 28, Cooperador 1); “(...) que não entendia e não sabia escrever” (Fragmento 29, Cooperador 2); “(...) eu não entendia, apenas o básico para entender" (Fragmento 30, Cooperador 3). O Cooperador 1 relata sua dificuldade com a pronúncia, evidenciando a diferença que há entre as pronúncias do português e do espanhol. Para o Cooperador 2, é evidente que lhe faltava domínio da gramática e que sua formação prévia não foi suficiente para as exigências acadêmicas com as quais se deparou e segue enfrentando. É possível notar uma mudança na percepção sobre o processo de aprendizagem do português por hispano-falantes, manifestada nos fragmentos que relatam o início da aprendizagem ainda em contexto paraguaio.

Percebe-se uma grande mudança na percepção dos Colaboradores, ao longo do tempo, sobre a demanda de esforço requerida para a aprendizagem de português língua estrangeira: o passado, quando se deu a aprendizagem formal, e o presente, momento de uso da língua. A experiência de um processo de interação no contexto brasileiro, com toda sua complexidade e exigência, se mostrou dificultosa, como já evidenciado pelos fragmentos anteriores, o que serviu de oportunidade e estímulo para os Colaboradores.

Embora seja natural haver diferença entre usar uma língua estrangeira em sala de aula e usá-la no país em que ela é falada, o que nos chamou a atenção foi a dificuldade dos estudantes de percebê-lo ou a falta de orientação que os preparasse melhor, do ponto de vista afetivo, durante o curso para as dificuldades que iriam experimentar. Possivelmente, isso é consequência de que, na maioria das vezes, não exista uma reflexão ao longo do percurso de formação sobre as necessidades específicas de um ou outro estudante e as implicações dessas necessidades sobre as futuras experiências que viverão.

Considerando o que dizem Clandinin e Connelly (2015) com relação a experiência como uma forma de adaptação dos indivíduos a seus ambientes, pensamos ser de importância ressaltar que depois de uma má experiência, as pessoas tendem a tomar caminhos alternativos. As pesquisadoras em pré-serviço, coautoras deste trabalho, também passaram por essa mesma experiência durante seu processo de formação no curso de graduação, inclusive, muitos de seus colegas desistiram por não se adaptarem às exigências do ambiente do curso.

No caso dos Cooperadores entrevistados, em todo momento procuraram melhorar o seu desempenho e vencer as dificuldades que se apresentavam, mas entendemos que uma preparação adequada de estudantes que tenham o mesmo objetivo - fazer pós-graduação no Brasil - deva não somente focar na preparação com relação a língua, mas também com as exigências do contexto relacionadas com a nova realidade que irão vivenciar, já que isso 
adicionaria maiores possibilidades de resiliência e de êxito ao processo e, embora essa não fosse a proposta do curso, poderia ser inserida no plano curricular.

Os Cooperadores relatam diversas dificuldades relacionadas ao processo de adaptação, como a dificuldade que pode ocasionar a proximidade entre o português e o espanhol e a dificuldade de domínio da compreensão e expressão orais para a interação social: “(...) tive muita dificuldade com os termos" (Fragmento 31, Cooperador 1); “(...) eles me ajudaram a falar” (Fragmento 32, Cooperador 2); “(...) envolver-se em conversas é o que mais me custou” (Fragmento 33, Cooperador 3).

O trabalho com os falsos cognatos faz parte do currículo do curso de português ministrado na FaCEN, local em que os Cooperadores cursaram as matérias de português I e II, por sua importância, mais ainda no caso do ensino de português para hispano-falantes em função da proximidade entre as línguas. Contudo, as confusões relatadas e explicitadas nos fragmentos indicam que esse trabalho poderia ser ampliado.

Com relação à compreensão e expressão orais, pensamos que embora não seja objetivo direto das matérias de português da FaCEN prepararem os estudantes para viverem, mesmo que temporariamente, no Brasil, um foco mais acentuado na interação com diferentes falantes nativos durante o desenvolvimento das matérias poderia ser de grande ajuda para aqueles que tenham a oportunidade de estudar ou trabalhar em território brasileiro.

O uso das novas tecnologias poderia ser um fator favorável na implantação de processos de interação entre estudantes e falantes nativos. Também poderia favorecer a ampliação do tempo de contato do estudante com a língua estudada, bem como ser um veículo da aprendizagem autônoma dos estudantes.

Quanto à escrita, os Cooperadores comentam nos fragmentos 34, 35 e 36 das narrativas que: “(...) na escrita, tive muitos problemas” (Cooperador 1); “(...) tive tanto erro que, tive que pagar para me ajudarem” (Cooperador 2); “(...) procurar as palavras e fazer uma frase corretamente em português ou pelo menos para que me entenderam me custou um pouco" (Cooperador 3). Percebe-se que a dificuldade com a expressão escrita, principalmente a escrita acadêmica, aponta para a necessidade de se criar oportunidades específicas, durante o processo de formação, para o desenvolvimento da redação, em geral, e da escrita acadêmica.

Como é muito complicado atender necessidades específicas em grupos heterogêneos, talvez fosse possível criar algum módulo especial somente para aqueles que tenham como objetivo cursar pós-graduação no Brasil, com aulas mais voltadas para as finalidades acadêmicas. $\mathrm{O}$ mesmo poderia ser feito para aqueles que necessitam fazer a prova do CELPEBras. 
Nos fragmentos 37 e 38 das narrativas dos Cooperadores 1 e 2, relacionados com questões culturais, a história foi um pouco diferente, tiveram uma melhor experiência: “(...) eu sempre gostei do português” (Cooperador 1); “(...) a questão cultural eu consigo” (Cooperador 2). O Brasil é relativamente familiar ao paraguaio, costuma ser opção corrente para as férias; a música brasileira é escutada com frequência nas casas dos paraguaios, as novelas brasileiras são sucesso no Paraguai, ou seja, há um conhecimento básico do que é a sociedade brasileira em função de uma maior exposição de produtos culturais brasileiros no Paraguai.

Uma preparação voltada para o desenvolvimento do diálogo e das habilidades interculturais, também teria lugar em um curso de português que contemple as necessidades de futuros estudantes de pós-graduação em território brasileiro. Os Colaboradores demonstram surpresa e grande admiração pela diversidade encontrada no Brasil, não somente interna, mas também de estrangeiros que frequentam as universidades brasileiras: “(...) você está em um grupo e você pode estar conversando com um jamaicano, com um alemão, há muita mistura" (Fragmento 39, Cooperador 1); “(...) foi difícil porque os brasileiros não são receptivos” (Fragmento 40, Cooperador 2); “(...) eles estavam interessados em pessoas que não eram brasileiras" (Fragmento 41, Cooperador 3).

Os Cooperadores demonstram maior facilidade de integração com outros estrangeiros que com brasileiros. O Cooperador 2 procurou estudantes hispano-falantes por se sentir mais à vontade com a língua e o Cooperador 3 foi procurado por brasileiros por sua condição de estrangeiro. As diferentes experiências dos Cooperadores 2 e 3, o primeiro relatando a falta de receptividade dos brasileiros e o segundo o interesse que despertou neles pode ter diversos fatores causais, desde questões relacionadas com empatias individuais até questões culturais, individuais, regionais e de contexto.

\section{Considerações finais}

Não foi objetivo deste trabalho avaliar o processo de ensino e aprendizagem, as atividades e técnicas pedagógicas que são realizadas no ensino de português da FACEN, mas, sim, centrarmos nas experiências dos ex-estudantes sobre seu processo de ensino aprendizagem e a utilização dessa aprendizagem quando em situação de uso real da língua em práticas acadêmicas e cotidianas.

Sabemos que a carga horária de 90 horas, dividida em dois semestres letivos, não é suficiente para levar um aprendiz de idioma estrangeiro a um nível superior de proficiência, 
mas necessitávamos saber quais são as experiências vividas por aqueles estudantes que, mesmo com uma formação insuficiente, se aventuram a desafios que lhes exigem além de sua preparação. Pensamos que essas experiências podem abrir possibilidades para um melhor entendimento das necessidades e dificuldades de estudantes paraguaios que cursam ou cursarão pós-graduação no Brasil e, assim, servir como elementos de reflexão e orientação para professores que ensinam português nas universidades paraguaias, e a estudantes que têm expectativas, quando não planos concretos, de viver uma experiência de estudo ou trabalho no Brasil.

Seria muito importante fornecer uma preparação adequada, não somente com relação a língua e suas especificidades, mas também aos desafios que enfrentarão no novo contexto, ao deixarem seu país, para agregar maiores possibilidades de êxito ao processo.

O que percebemos, quando lemos os fragmentos das narrativas de cada Cooperador, é a existência de uma insuficiência da carga horária, o que nos leva a conclusão de que o aumento da carga horária seria um fator importante de melhoria das condições de uso da língua em contexto real. Tendo em conta os desafios dos professores com as restrições de tempo e as padronizações curriculares dos estudantes, pensamos que é importante incentivar os alunos no desenvolvimento de uma aprendizagem mais autônoma e, se possível, com o uso das novas tecnologias.

Outro ponto importante seria que os professores trabalhassem, em sala de aula, as questões relacionadas com a nova realidade da qual participarão os estudantes, mostrando um panorama mais realista aos estudantes da cultura brasileira e dos diversos sotaques do português do Brasil.

Também pensamos que o desenvolvimento de habilidades acadêmicas, nos cursos de PLE no Paraguai, tem, nas práticas de aula, uma lacuna entre a formação e a demanda de contexto para aqueles que se aventuram a uma pós-graduação no Brasil. Talvez seja importante criar módulos específicos destinados a esses estudantes, bem como aqueles que pretendem fazer a prova do CELPE-Bras.

O preparo de recursos, materiais e atividades tangenciais à aula de PLE, que possam ser acessados a partir de certas indicações inseridas nos materiais didáticos, também podem servir como reforço e ampliação da aprendizagem.

As narrativas também nos chamaram a atenção para a necessidade de aprofundar o trabalho com os falsos cognatos e a necessidade de se oferecer oportunidades de interação com falantes nativos, de diversas regiões, de maneira mais sistematizada, possivelmente com a 
utilização das novas tecnologias para promover a interação com nativos por meio de atividades na modalidade Tandem.

\section{REFERÊNCIAS}

CLANDININ, D. J.; CONNELLY, F. M. Pesquisa Narrativa: experiências e história qualitativa. Uberlândia: EDUFU - tradução: Grupo de Pesquisa narrativa e Educação de professores ILEEL/UFU. 2da. Edição, 2015.

CUNHA, R. C. da. A pesquisa narrativa: uma estratégia sobre o ser professor. Teresina: Programa de Mestrado em Educação (PPGED) da Universidade Federal do Piauí (UFPI), 2009.

DEWEY, J. Experience and Education. New York: Collier Books, 1938.

WEXELL-MACHADO, L. E.; MATTAR, J. Aprendizagem Tangencial: Revisão de Literatura sobre os Usos Contemporâneos do Conceito. Rio de Janeiro: Revista

EducaOnline, v. 11, n. 1 - Universidade Federal do Rio de Janeiro, 2017. Disponível em: https://tinyurl.com/yxgw9sgc

WEXELL-MACHADO, L. E.; ALCARAZ, L.; BENITEZ, I. Narrativas de Aprendizagem de ex-estudantes de português como língua estrangeira, Mendeley Data, v. 2, 2019. Disponível em: http://dx.doi.org/10.17632/f5yy59xpgy.1

\section{Como citar este artigo:}

WEXELL-MACHADO, Luís Eduardo; ALCARAZ, Lilian; BENÍTEZ, Irma. Relatos de experiências de ex-estudantes de português como língua estrangeira: a coconstrução do conhecimento por meio da pesquisa narrativa. Rev. EntreLínguas, Araraquara, v. 5, n. 1, p. 39-56, jan./jun. 2019. E-ISSN: 2447-3529. DOI: 10.29051/el.v5i1.12599

Submetido em: $30 / 11 / 2018$

Revisões requeridas: 28/02/2019

Aprovado em: 15/03/2019

Publicado em: 30/04/2019 